\title{
Effect of Afghan Senjed (Elaeagnus Angustifolia L.) Leaves Aqueous alcoholic Extract on Blood Glucose Level of Diabetic Rats
}

\author{
Hamida Sadat ${ }^{1}$, Kawsar Alami' , Sayed Yousof Mousavi ${ }^{2, *}$
}

Hamida Sadat ${ }^{1}$, Kawsar Alami', Sayed Yousof Mousavi ${ }^{2, *}$

${ }^{1}$ Research and technology center, Khatam AlNabieen University, Karte 4, 1st street, Kabul, AFGHANISTAN.

${ }^{2}$ Department of physiology, Khatam AlNabieen university, Karte 4, 1st street, Kabul, AFGHANISTAN.

\section{Correspondence}

\section{Sayed Yousof Mousavi}

Department of physiology, Khatam Al-

Nabieen university, Karte 4, 1st street,

Kabul, AFGHANISTAN.

Phone no: +93(0)796850084;

E-mail: mousavi.knurtc@knu.edu.af

History

- Submission Date: 27-05-2020;

- Review completed: 29-06-2020;

- Accepted Date: 06-07-2020.

DOI : 10.5530/pj.2020.12.170

Article Available online

http://www.phcogj.com/v12/i6

\section{Copyright}

(C) 2020 Phcogj.Com. This is an openaccess article distributed under the terms of the Creative Commons Attribution 4.0 International license.

\begin{abstract}
Introduction: Diabetes mellitus is a metabolic disorder, which affects many people throughout the world. The inefficacy and multiple side effects of most synthetic anti-diabetic drugs are reported by various studies. Thus, many researchers are focused on the use of medicinal plants as safe and potent anti-hyperglycemic drugs. The aim of this study is the evaluation of the effect of Afghan senjed (Elaeagnus Angustifolia L.) leaves aqueous alcoholic extract on blood glucose level of diabetic rats. Methods: Rats were divided into 6 groups: normal, diabetic, metformin and Elaeagnus Angustifolia leaves extract (EALE) groups, which received 200,400 and $800 \mathrm{mg} / \mathrm{kg}$ doses of extract for 15 days. Diabetes was induced by single dose intraperitoneal administration of streptozotocin (STZ). During treatment, the effect of single and repeated oral administration of EALE on blood glucose level of diabetic rats was evaluated. On last day, the effect of EALE on oral glucose tolerance test (OGTT) was also assessed. Results: All doses of EALE showed significant reduction in blood glucose level, an improvement of glucose tolerance and enhancement in body weight. Conclusion: EALE possessed an antihyperglycemic property in diabetic rats.

Key words: Elaeagnus Angustifolia leaves, Blood glucose level, Glucose tolerance, Streptozotocin, Diabetic rats.
\end{abstract}

\section{INTRODUCTION}

Diabetes mellitus is a chronic metabolic disorder, which affects many people throughout the world. ${ }^{1}$ This disorder is characterized by hyperglycemia, insufficient endogenous insulin secretion or function, as well as resistance to insulin in target organs. ${ }^{2,3}$ The main clinical and diagnostic sign of diabetes, is hyperglycemia, which is considered as the major cause of mortality and morbidity in diabetic patients. ${ }^{4,5}$ Therefore, the main cause of diabetes treatment is the control of hyperglycemia. ${ }^{6}$

Because synthetic anti-hyperglycemic drugs have multiple side effects, the consideration on the use of complementary and alternative medicine, especially medicinal plants is increasing. ${ }^{6}$ Senjed (Elaeagnus Angustifolia L.) is the one of useful medicinal plants, which is widely used for treatment of different diseases. ${ }^{7}$ All parts of senjed including flower, fruit, bark and leaves have different pharmacological and biological effects. ${ }^{8}$ Senjed leaves contains most useful constituents such as flavonoids, alkaloids, steroids, terpenoids, as well as beta-sitosterol. ${ }^{9}$ It has been shown that flavonoids and phenolic compounds of senjed leaves are greater than its flower, especially in methanolic and ethanolic extracts. ${ }^{10}$

Studies have been shown that senjed fruit polysaccharide could decrease the blood glucose and lipids in diabetic rats. ${ }^{11}$ In addition, there are some reports from in-vitro study, which are shown that senjed leaves methanolic extract (ME) could inhibit the alpha-glucosidase and alpha-amylase enzymes activity. Thus, it may be potentially useful for treatment of diabetes, especially hyperglycemia. ${ }^{12}$ However, despite the presence of beneficial and significant constituents in senjed leaves, there is not any evidence of an in-vivo study on its antihyperglycemic property. Therefore, this study investigates the effect of EALE on blood glucose level of diabetic rats.

\section{MATERIALS AND METHODS}

\section{Plant material and extraction}

Fresh senjed leaves were collected from Khume Hendo, Logar province of Afghanistan. The leaves were dried and grinded. $100 \mathrm{~g}$ of its powder were macerated in $80 \%$ aqueous methanol (AM) for 72 hours in ambient temperature. The mixture was then filtered and evaporated in a vacuum rotary (Vargha Tajhiz, Iran). ${ }^{13}$

\section{Animals}

Sixty-six adult Sprague-Dawley male rats weighing between 180 and $220 \mathrm{~g}$, randomly selected from KNURTC, were housed in Plexy-glass cages with free access to food and water. Animals were kept under stable room temperature $\left(23 \pm 2^{\circ} \mathrm{C}\right)$ and a 12 hours light/dark cycle (the light period started at 7 a.m.) The experimental protocol approved by the ethic research board of Khatam Al-Nabieen University and were conducted following the ethical guidelines set by the $8^{\text {th }}$ edition of National Institute of Health



Cite this article: Sadat H, Alami K, Mousavi SY. Effect of Afghan Senjed (Elaeagnus Angustifolia L.) Leaves Aqueous alcoholic Extract on Blood Glucose Level of Diabetic Rats. Pharmacogn J. 2020;12(6):1218-22. 
(NIH) guide for the care and use of laboratory animals. Rats were carefully handled to minimize unwanted stress during housing and experiments.

\section{Induction of diabetes}

The experimental diabetes was induced by a single intraperitoneal (i.p.) administration of streptozotocin (STZ) (Sigma-Aldrich, USA), at a dose of $55 \mathrm{mg} / \mathrm{kg}$ after 8 hours fasting. The STZ was dissolved in $0.1 \mathrm{M}$ sodium citrate buffer (pH: 4.5). 72 hours later, diabetes was confirmed by determining the blood glucose level. The rats with $200 \mathrm{mg} / \mathrm{dl}$ blood glucose level were only considered for the experiment.

\section{Experimental groups}

Rats were randomly divided into 6 groups $(\mathrm{n}=6)$ : (1) Normal group, non-diabetic rats were received normal saline orally for 15 days; (2) Diabetic group (as negative control group), diabetic rats were received normal saline orally for 15 days; (3) Metformin group (as positive control group), diabetic rats were received $500 \mathrm{mg}$ metformin ${ }^{14}$ (Merck, Germany) orally for 15 days; (4-6) EALE 200, 400 and $800 \mathrm{mg} / \mathrm{kg}$ (Treatment groups), diabetic rats were received EALE orally for 15 days.

\section{Procedures}

For evaluation of single oral administration effect, on day 1 (First day after confirmation of diabetes induction), normal saline, metformin or EALE was administered to rats and their blood glucose level was measured during 6 hours $(0,1,2,4$ and 6 hours). For evaluation of repeated oral administration effect, normal saline, metformin or EALE were administered once daily for 15 days and blood glucose level was measured on $0,2,4,7$ and 15 days. ${ }^{15}$ After 15 days treatment, rats were fasted and their fasting blood glucose was measured. For evaluation of OGTT, a glucose solution $(2 \mathrm{~g} / \mathrm{kg})$ was orally administrated to rats and their blood glucose level was measured on 30,60 and 120 min after glucose load. ${ }^{16}$ All experiments were performed after 8 hours fasting and blood glucose level was measured by blood withdrawn from the tail of rats using strips and glucometer (On call plus, Acon, USA). The body weight of all rats was determined on 0,2, 4, 7 and 15 days and changes in body weight were calculated.

\section{Statistical analysis}

The statistical analysis was done with Graph pad prism (6.07) software. The blood glucose level and body weight were analyzed by Two-way ANOVA, followed by Dunnets test multiple comparisons. Difference between body weight of different groups was analyzed by non-parametric Kruskal Wallis test. The difference amongst means was considered statistically significant if the $\mathrm{P}<0.05$. The results are expressed as mean \pm SEM.

\section{RESULTS}

\section{Effect of single oral administration of EALE on blood glucose level}

The blood glucose level of all groups was evaluated on $0,1,2,4$ and 6 hours after single oral administration. There was a significant difference in blood glucose level between normal and diabetic groups on $0,1,2$, 4 and 6 hours. In addition, the blood glucose level of all EALE-treated groups $(200,400$ and $800 \mathrm{mg} / \mathrm{kg}$ ), and also metformin group was significantly decreased on 1, 2, 4 and 6 hours, as compared with diabetic group (Table 1).

\section{Effect of repeated oral administration of EALE on blood glucose level}

The blood glucose level of all groups was evaluated on $0,2,4,7$ and 15 days during repeated oral administration. There was a significant difference in blood glucose level between normal and diabetic groups on $0,2,4,7$ and 15 days. In addition, the blood glucose level of metformin group was significantly decreased on 2, 4, 7 and 15 days, as compared with diabetic group. Also, there was a significant difference in blood glucose level between all EALE-treated groups (200, 400 and $800 \mathrm{mg} / \mathrm{kg}$ ) and diabetic group on day 15 . The blood glucose level of EALE $800 \mathrm{mg} / \mathrm{kg}$ group was also significantly decreased on day 4 and 7 as compared with diabetic group (Table 2).

\section{Effect of EALE on OGTT}

The blood glucose level of all groups was evaluated on 30, 60 and 120 min after oral glucose load. There was a significant difference in blood glucose level between normal and diabetic groups on $0,30,60$ and $120 \mathrm{~min}$. In addition, the blood glucose level of metformin group was significantly decreased on $0,30,60$ and $120 \mathrm{~min}$, as compared with diabetic group. Also, there was a significant difference in blood glucose level between EALE $800 \mathrm{mg} / \mathrm{kg}$ and diabetic groups on 0, 30, 60 and 120 min. The blood glucose level of EALE 200 and $400 \mathrm{mg} / \mathrm{kg}$ group was also significantly decreased on 0 and $30 \mathrm{~min}$ as compared with diabetic group (Table 3 ).

\section{Effect of EALE on body weight}

The body weight of all groups was evaluated on $0,2,4,7$ and 15 days. There was a significant difference in body weight between normal and diabetic groups on 2, 4, 7 and 15 days. In addition, the metformin and EALE $800 \mathrm{mg} / \mathrm{kg}$ groups was significantly showed weight gain after treatment. Also, there was a significant difference in body weight of metformin and all EALE-treated groups on day 15 (Table 4).

Table 1: Effect of single oral administration of EALE on blood glucose level.

\begin{tabular}{|c|c|c|c|c|c|}
\hline \multirow[t]{2}{*}{ Groups } & \multicolumn{5}{|c|}{ Blood glucose level (mg/dl) } \\
\hline & 0 Hour & 1 Hour & 2 Hour & 4 Hour & 6 Hour \\
\hline Normal & $78.00 \pm 1.98^{* * * *}$ & $77.17 \pm 3.24^{* * * *}$ & $80.50 \pm 6.11^{* * * *}$ & $84.17 \pm 3.54^{* * * x}$ & $80.67 \pm 1.89^{* * * * x}$ \\
\hline Diabetic & $579.00 \pm 15.64$ & $573.50 \pm 15.16$ & $505.17 \pm 28.11$ & $507.83 \pm 18.78$ & $423.50 \pm 27.125$ \\
\hline Metformin & $552.17 \pm 30.48$ & $369.50 \pm 25.42^{+*+* x}$ & $181.17 \pm 16.34^{* \times *+}$ & $130.67 \pm 22.71^{* * * * *}$ & $111.67 \pm 16.36^{* * * *}$ \\
\hline EALE $(200 \mathrm{mg} / \mathrm{kg})$ & $513.67 \pm 18.80$ & $476.50 \pm 26.57^{* *}$ & $357.17 \pm 32.89^{9 \times * x}$ & $332.17 \pm 26.43^{* * * x}$ & $315.50 \pm 27.19^{* * * x}$ \\
\hline EALE $(400 \mathrm{mg} / \mathrm{kg})$ & $510.00 \pm 35.10$ & $375.33 \pm 19.86^{*+*+*}$ & $326.67 \pm 19.10^{* *+* *+}$ & $317.67 \pm 20.91^{* * * *+}$ & $297.00 \pm 11.16^{* x+x}$ \\
\hline EALE $(800 \mathrm{mg} / \mathrm{kg})$ & $518.83 \pm 7.43$ & $367.67 \pm 10.10^{*+x+*}$ & $334.17 \pm 6.29^{*+x+x}$ & $292.33 \pm 6.94^{x+x+x}$ & $290.00 \pm 9.66^{6+x+x}$ \\
\hline
\end{tabular}

Data are shown as Mean \pm SEM. EALE: Elaeagnus angustifolia leaves extract. ${ }^{* * *}: \mathrm{P}<0.01,{ }^{* * * *}: \mathrm{P}<0.001,{ }^{* * * * *}: \mathrm{P}<0.0001$ as compared with diabetic group. 
Table 2: Effect of repeated oral administration of EALE on blood glucose level.

\begin{tabular}{|c|c|c|c|c|c|}
\hline \multirow[t]{2}{*}{ Groups } & \multicolumn{5}{|c|}{ Blood glucose level (mg/dl) } \\
\hline & 0 Day & 2 Day & 4 Day & 7 Day & 15 Day \\
\hline Normal & $65.50 \pm 2.47^{*+* * *}$ & $67.50 \pm 1.59^{*+* * x}$ & $71.17 \pm 3.97^{*+* * *}$ & $76.33 \pm 4.42^{* * * *}$ & $76.00 \pm 1.93^{*+x+x}$ \\
\hline Diabetic & $408.17 \pm 31.71$ & $377.00 \pm 22.63$ & $375.33 \pm 26.19$ & $372.17 \pm 30.34$ & $446.50 \pm 29.10$ \\
\hline Metformin & $396.33 \pm 14.34$ & $92.00 \pm 2.92^{* * * x}$ & $71.00 \pm 6.55^{* * * *}$ & $79.00 \pm 6.01^{* * * *}$ & $159.33 \pm 15.07^{*+x+x}$ \\
\hline EALE $(200 \mathrm{mg} / \mathrm{kg})$ & $379.50 \pm 12.63$ & $325.17 \pm 25.33$ & $350.17 \pm 16.38$ & $312.33 \pm 23.65$ & $329.17 \pm 19.05^{* * *}$ \\
\hline EALE $(400 \mathrm{mg} / \mathrm{kg})$ & $381.33 \pm 11.57$ & $323.17 \pm 19.79$ & $333.33 \pm 19.29$ & $313.67 \pm 15.97$ & $341.00 \pm 33.12^{* *}$ \\
\hline EALE $(800 \mathrm{mg} / \mathrm{kg})$ & $422.17 \pm 22.82$ & $354.83 \pm 37.79$ & $303.83 \pm 24.98^{*}$ & $270.00 \pm 10.97^{* *}$ & $354.00 \pm 13.06^{* *}$ \\
\hline
\end{tabular}

Data are shown as Mean \pm SEM. EALE: Elaeagnus angustifolia leaves extract. ${ }^{*}: \mathrm{P}<0.05,{ }^{* *}: \mathrm{P}<0.01,{ }^{* * *}: \mathrm{P}<0.001,{ }^{* * * *}: \mathrm{P}<0.0001$ as compared with diabetic group.

Table 3: Effect of EALE on OGTT.

\begin{tabular}{|c|c|c|c|c|}
\hline \multirow[t]{2}{*}{ Groups } & \multicolumn{4}{|c|}{ Blood glucose level (mg/dl) } \\
\hline & $0 \mathrm{Min}$ & $30 \mathrm{Min}$ & $60 \mathrm{Min}$ & 120 Min \\
\hline Normal & $76.00 \pm 1.93^{* *+*}$ & $83.67 \pm 3.33^{*+x+x}$ & $90.83 \pm 4.24^{*+* * *}$ & $81.00 \pm 4.07^{* *+*}$ \\
\hline Diabetic & $446.50 \pm 29.54$ & $503.33 \pm 34.55$ & $420.33 \pm 27.60$ & $404.17 \pm 25.98$ \\
\hline Metformin & $159.33 \pm 15.07^{* * * *}$ & $254.17 \pm 13.13^{* * * *}$ & $280.33 \pm 16.64^{* * *}$ & $266.00 \pm 27.19^{* * *}$ \\
\hline EALE (200 mg/kg) & $329.17 \pm 19.05^{* *}$ & $421.83 \pm 33.64^{*}$ & $346.67 \pm 21.59$ & $333.00 \pm 21.35$ \\
\hline EALE (400 mg/kg) & $337.00 \pm 34.35^{* *}$ & $398.00 \pm 35.73^{* *}$ & $353.67 \pm 13.73$ & $287.50 \pm 16.84^{* *}$ \\
\hline EALE (800 mg/kg) & $354.00 \pm 13.06^{*}$ & $401.33 \pm 21.72^{* *}$ & $338.50 \pm 17.65^{\star}$ & $260.50 \pm 26.23^{* * * * x}$ \\
\hline
\end{tabular}

Data are shown as Mean \pm SEM. EALE: Elaeagnus angustifolia leaves extract. " $: \mathrm{P}<0.05,{ }^{* *}: \mathrm{P}<0.01,{ }^{, * *}: \mathrm{P}<0.001,{ }^{* * * *}: \mathrm{P}<0.0001$ as compared with diabetic group.

Table 4: Effect of EALE on body weight.

\begin{tabular}{|c|c|c|c|c|c|c|}
\hline \multirow[t]{2}{*}{ Groups } & \multicolumn{5}{|c|}{ Body weight (g) } & \multirow{2}{*}{$\begin{array}{c}\text { Weight gain/lost } \\
\text { 0-15 Day }\end{array}$} \\
\hline & 0 Day & 2 Day & 4 Day & 7 Day & 15 Day & \\
\hline Normal & $186.33 \pm 2.55$ & $193.33 \pm 2.50^{* *}$ & $195.50 \pm 2.58^{* *}$ & $200.67 \pm 2.91^{* * * *}$ & $205.83 \pm 2.63^{* * * *}$ & $19.50 \pm 1.26^{* * * *}$ \\
\hline Diabetic & $178.67 \pm 1.93$ & $175.00 \pm 1.97$ & $174.00 \pm 2.76$ & $167.67 \pm 2.01$ & $141.50 \pm 5.23^{* x+x}$ & $-37.17 \pm 4.63$ \\
\hline Metformin & $179.33 \pm 1.54$ & $178.17 \pm 3.34$ & $176.33 \pm 4.44$ & $179.00 \pm 2.95$ & $188.67 \pm 1.93^{* * * *}$ & $9.33 \pm 2.27^{* *}$ \\
\hline EALE $(200 \mathrm{mg} / \mathrm{kg})$ & $177.33 \pm 4.52$ & $174.33 \pm 3.64$ & $173.50 \pm 4.61$ & $169.50 \pm 5.60$ & $172.83 \pm 6.05^{*+*+*}$ & $-4.5 \pm 3.51$ \\
\hline EALE $(400 \mathrm{mg} / \mathrm{kg})$ & $176.50 \pm 4.01$ & $168.83 \pm 1.25$ & $171.50 \pm 3.09$ & $150.83 \pm 8.06$ & $169.33 \pm 6.23^{* * * *}$ & $-7.17 \pm 6.29$ \\
\hline EALE $(800 \mathrm{mg} / \mathrm{kg})$ & $177.67 \pm 3.82$ & $177.67 \pm 3.82$ & $178.83 \pm 5.79$ & $172.50 \pm 3.74$ & $177.33 \pm 4.52^{* * * x}$ & $-0.33 \pm 1.67^{*}$ \\
\hline
\end{tabular}

Data are shown as Mean \pm SEM. EALE: Elaeagnus angustifolia leaves extract. ${ }^{*}: \mathrm{P}<0.05,{ }^{* *}: \mathrm{P}<0.01,{ }^{* * * *}: \mathrm{P}<0.0001$ as compared with diabetic group.

\section{DISCUSSION}

In this study, the effect of Afghan EALE on blood glucose level of STZ-induced diabetic rats was evaluated. STZ is a cytotoxic analogue of glucose which is used for induction of type 1 and 2 diabetes in animals. Administration of this cytotoxic compound is leads to DNA destruction, production of free radicals and destruction of pancreatic beta cells. As a result, reduction in insulin secretion, hyperglycemia and body weight loss develops. ${ }^{17,18}$

Similarly, this study indicated that single dose administration of STZ could increase the blood glucose level and body weight loss in diabetic rats. Thus, one can conclude that administration of STZ in this study developed experimental model of diabetes.

According to obtained data in this study, single oral administration of EALE in all doses could significantly decrease the blood glucose level in diabetic rats. However, the effect of repeated oral administration of EALE was different in a dose-dependent manner. Only high dose (800 $\mathrm{mg} / \mathrm{kg}$ ) of EALE could significantly decrease the blood glucose level on different days (4, 7 and 15). Whereas, low doses (200 and $400 \mathrm{mg} / \mathrm{kg}$ ) of EALE were effective on blood glucose level only on day 15. In addition, the body weight was increased in all EALE-treated groups on day 15, but only $800 \mathrm{mg} / \mathrm{kg}$ dose of EALE could significantly compensate the body weight loss in diabetic rats. Therefore, single oral administration of both low and high doses of EALE can decrease the blood glucose level acutely. Besides, the long-term repeated oral administration of EALE is effective on blood glucose level, even in low doses. Whereas, its high dose repeated oral administration can significantly decrease the blood glucose level of diabetic rats, even in short-term administration period.

Similarly, a previous in-vitro study has been shown that ME of senjed leaves can significantly inhibit the alpha-glucosidase and alpha-amylase enzymes. The alpha-glucosidase inhibitory property of senjed leaves extract was much greater. They concluded that those properties are resulted from the presence of benzoic compounds (especially vanillic acid and 4-hydroxy benzoic acid) in senjed leaves extract, because phenolic acids are moderate inhibitors of alpha-amylase and potent inhibitors of alpha-glucosidase enzymes. ${ }^{12}$ Alpha-glucosidase inhibitor drugs or plants causes delayed absorption of carbohydrates into blood. As a result, they can decrease the blood glucose level. ${ }^{19,20}$ Therefore, the anti-hyperglycemic effects of EALE can be explained by its alphaglucosidase inhibitory property.

Besides, the EALE in this study, especially in high doses, could improve glucose tolerance in diabetic rats. The effect of EALE high dose on OGTT was greater than metformin. Metformin is a biguanide which has insulin sensitizing effect and potent hypoglycemic property. ${ }^{14}$ As OGTT is a test for evaluation of insulin release and sensitivity, ${ }^{21}$ one can conclude that EALE can increase the insulin release and decrease 
the insulin resistance. So, it may be considered as an effective antihyperglycemic drug, with low side effects.

In addition to presence of benzoic compounds such as vanillic acid in EALE, ${ }^{12}$ there is some reports which are shown that senjed leaves contain flavonoids, alkaloids, steroids, terpenoids, as well as betasitosterol. ${ }^{9}$ Previous studies shown that vanillic acid could decrease the insulin resistance and the hyperglycemia effectively. ${ }^{22,23}$ Also, there are some reports which are indicate that the most of flavonoids have potent alpha-glucosidase inhibitory property and anti-hyperglycemic effect, as well as improving glucose tolerance. ${ }^{1924}$ In addition, betasitosterol can decrease the intestinal absorption of glucose, activate the insulin receptors and increase the blood insulin level by regeneration of pancreatic beta cells. This compound also has anti-oxidant property and can destroy the reactive oxygen species. Beta-sitosterol also can increase the GLUT4 level in cytosol and plasma membrane of fat tissues in diabetic rats. All of these lead to a decrease in blood glucose level. ${ }^{25,26}$ Therefore, the anti-hyperglycemic effects and improvement of glucose tolerance may have resulted from the presence of flavonoids, betasitosterol and benzoic compounds, as well as insulin-enhancing effects and alpha-glucosidase inhibitory property.

\section{CONCLUSION}

In summary, one can conclude that EALE has anti-hyperglycemic property and can improve glucose tolerance. Thus, it may be considered as an effective anti-hyperglycemic drug, with low side effects.

\section{ACKNOWLEDGEMENTS}

This work is supported by the research and technology center of Khatam Al-Nabieen University (KNURTC) Kabul, Afghanistan. We thank all officials for their valuable support for providing the equipment and facilities for this study.

\section{REFERENCES}

1. Cho N, Shaw JE, Karuranga S, Huang Y, da Rocha Fernandes JD, Ohlrogge AW et al. IDF Diabetes Atlas: Global estimates of diabetes prevalence for 2017 and projections for 2045. Diabetes Res Clin Pract. 2018;138:271-81.

2. Lim KH, Han JH, Lee JY, Park YS, Cho YS, Kang KD, et al. Assessment of antidiabetogenic potential of fermented soybean extracts in streptozotocininduced diabetic rat. Food Chem Toxicol. 2012;50(11):3941-8.

3. Damasceno DC, Netto AO, lessi IL, Gallego FQ, Corvino SB, Dallaqua B, et al. Streptozotocin-induced diabetes models: pathophysiological mechanisms and fetal outcomes. BioMed Res Int. 2014;11.

4. Zaccardi F, Webb DR, Yates T, Davies MJ. Pathophysiology of type 1 and type 2 diabetes mellitus: a 90-year perspective. Postgrad Med J. 2016;92(1084):63-9.

5. Prabhakar PK, Kumar A, Doble M. Combination therapy: a new strategy to manage diabetes and its complications. Phytomedicine. 2014;21:123-30.

6. Patel DK, Kumar R, Laloo D, Hemalatha S. Natural medicines from plant source used for therapy of diabetes mellitus: An overview of its pharmacological aspects. Asian Pac J Trop Dis. 2012;2:239-50.

7. Tehranizadeh ZA, Baratian A, Hosseinzadeh H. Russian olive (Elaeagnus angustifolia) as a herbal healer. Biolmpacts. 2016;6(3):155.
8. Cheraghipoor M, Maghsoodlou MT, Faghihi MR. A Green, Novel and Efficient Protocol for the Preparation of Diverse 4 H-Pyrans: The First Report on the Catalytic Activity of Water Extract of Elaeagnus angustifolia Leaves in Organic Reactions. Polycycl Aromat Compd. 2019:1-0.

9. Azeez RA, Abaas IS, Kadhim EJ. Isolation and Characterization of $\beta$-sitosterol from Elaeagnus angustifolia cultivated in Iraq. Asian J Pharm Clin Res. 2018;11(11):442-6.

10. Saboonchian F, Jamei R, Sarghein SH. Phenolic and flavonoid content of Elaeagnus angustifolia L. (leaf and flower). Avicenna J Phytomed. 2014;4(4):231.

11. Wang Y, Zou HM, Sun C, Guo T, Feng ZP. Hypoglycemic potential of Elaeagnus angustifolia fruit polysaccharide on streptozotocin-induced type 2 diabetic mice. Bangladesh J Pharmacol. 2018;13(4):297-301.

12. Saltan FZ. In vitro $\alpha$-Glucosidase and $\alpha$-Amylase Enzyme Inhibitory Effects in Elaeagnus angustifolia Leaves Extracts. Eurasian J Anal Chem. 2017;12(2):11726.

13. Incilay G. Volatile Composition, Antimicrobial and Antioxidant Properties of Different Parts from Elaeagnus angustifolia L. J Essent Oil Bear PI. 2014;17(6):1187-202.

14. Widyawati T, Yusoff NA, Asmawi MZ, Ahmad M. Antihyperglycemic effect of methanol extract of Syzygium polyanthum (Wight.) leaf in streptozotocininduced diabetic rats. Nutrients. 2015;7(9):7764-80.

15. Farid O, Hebi M, Ajebli M, Hidani AE, Eddouks M. Antidiabetic effect of Ruta montana L. in streptozotocin-induced diabetic rats. J Basic Clinical Physiol Pharmacol. 2017;28(3):275-82.

16. Wisetmuen $E$, Pannangpetch $P$, Kongyingyoes $B$, Kukongviriyapan $U$ Yutanawiboonchai $W$, Itharat $A$. Insulin secretion enhancing activity of roselle calyx extract in normal and streptozotocin-induced diabetic rats. Pharmacog Res. 2013;5(2):65.

17. Eleazu CO, Eleazu KC, Chukwuma S, Essien UN. Review of the mechanism of cell death resulting from streptozotocin challenge in experimental animals, its practical use and potential risk to humans. J Diabetes Metab Disord 2013;12(1):60.

18. Deeds MC, Anderson JM, Armstrong AS, Gastineau DA, Hiddinga HJ, Jahangir A, et al. Single dose streptozotocin-induced diabetes: considerations for study design in islet transplantation models. Lab Anim. 2011;45:131-40.

19. Söhretoğlu D, Sari S. Flavonoids as alpha-glucosidase inhibitors: mechanistic approaches merged with enzyme kinetics and molecular modelling. Phytochem Rev. 2019:1-2.

20. Benalla W, Bellahcen S, Bnouham M. Antidiabetic medicinal plants as a source of alpha glucosidase inhibitors. Curr Diabetes Rev. 2010;6(4):247-54

21. Stumvoll M, Mitrakou A, Pimenta W, Jenssen T, Yki-Järvinen HA, Van Haeften T, et al. Use of the oral glucose tolerance test to assess insulin release and insulin sensitivity. Diabetes Care. 2000;23(3):295-301.

22. Vinothiya K, Ashokkumar N. Modulatory effect of vanillic acid on antioxidant status in high fat diet-induced changes in diabetic hypertensive rats. Biomed Pharmacother. 2017;87:640-52.

23. Chang WC, Wu JS, Chen CW, Kuo PL, Chien HM, Wang YT, et al. Protective effect of vanillic acid against hyperinsulinemia, hyperglycemia and hyperlipidemia via alleviating hepatic insulin resistance and inflammation in high-fat diet (HFD)-fed rats. Nutrients. 2015;7(12):9946-59.

24. Vinayagam R, Xu B. Antidiabetic properties of dietary flavonoids: a cellular mechanism review. Nutr Metab. 2015;12(1):60.

25. Gupta R, Sharma AK, Dobhal MP, Sharma MC, Gupta RS. Antidiabetic and antioxidant potential of $\beta$ - sitosterol in streptozotocin - induced experimental hyperglycemia. J Diabetes. 2011;3(1):29-37.

26. Ponnulakshmi R, Shyamaladevi B, Vijayalakshmi P, Selvaraj J. In silico and in vivo analysis to identify the antidiabetic activity of beta sitosterol in adipose tissue of high fat diet and sucrose induced type-2 diabetic experimental rats. Toxicol Mech Methods. 2019;29(4):276-90. 


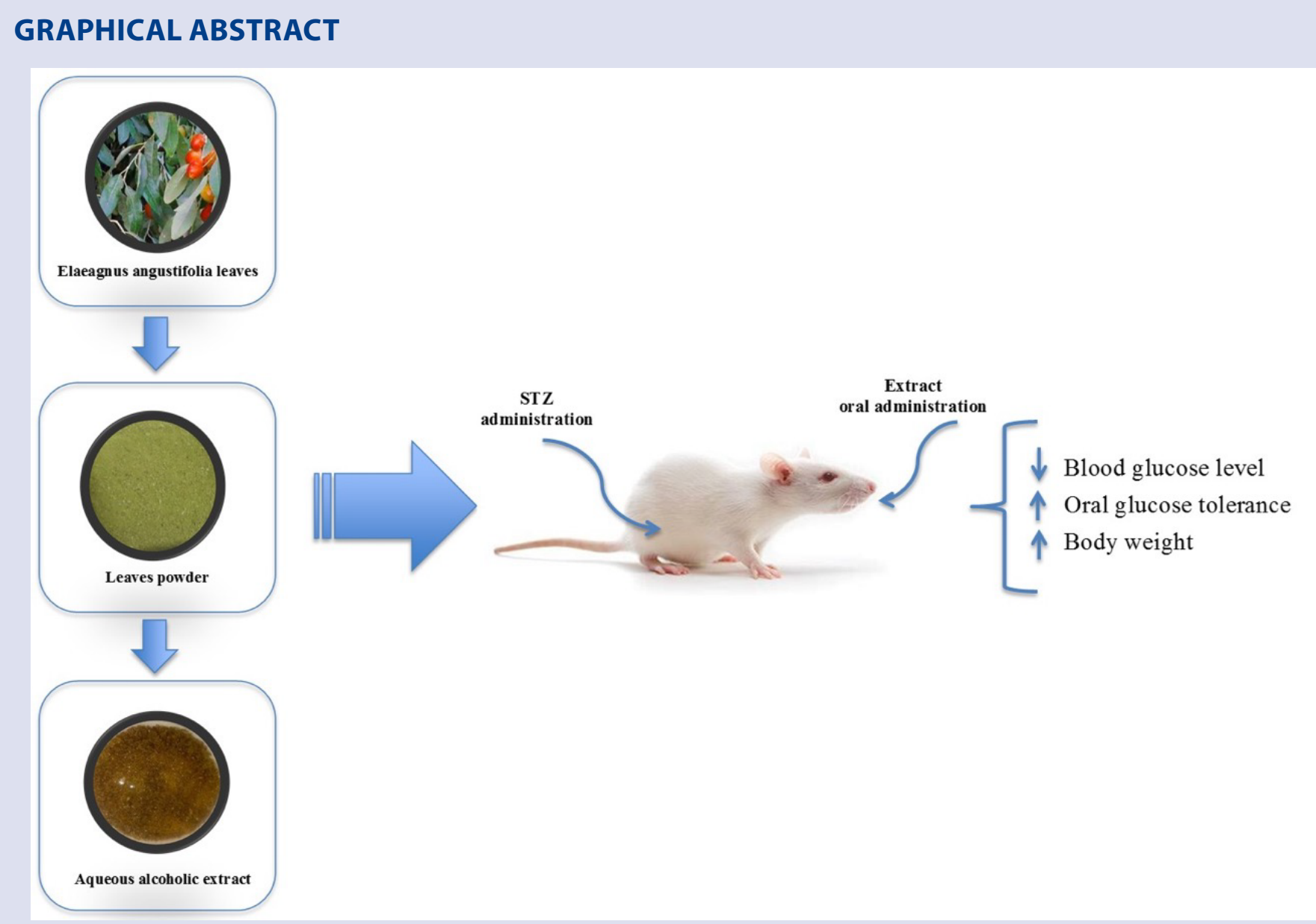

\section{ABOUT AUTHORS}

- Hamida Sadat: Is a student in the medical faculty of Khatam Al-Nabieen University. She worked as a researcher in the Research and Technology Center of Khatam Al-Nabieen University.

- Kawsar Alami: Is a student in the medical faculty of Khatam Al-Nabieen University. She worked as a researcher and lecturer in the Research and Technology Center of Khatam Al-Nabieen University. She has researches mainly focused on the physiological and pharmacological aspects of medicinal plants. She has experience in the methods of learning and memory studies.

- Sayed Yousof Mousavi: Is a Ph.D. of medical physiology and Professor in the Faculty of Medical Sciences, Khatam AlNabieen University. He is positioned as vice-chancellor of research and technology head of Research and Technology Center of Khatam Al-Nabieen University. He has experience in the area of Brain cannulation in rats, Brain slices, Whole-cell patchclamp recording methods, Extra- and intracellular recording methods, Methods of learning and memory studies, Methods of the animal model of addiction. His research interest: Network Physiology, Synaptic plasticity and Metaplasticity.

Cite this article: Sadat H, Alami K, Mousavi SY. Effect of Afghan Senjed (Elaeagnus Angustifolia L.) Leaves Aqueous alcoholic Extract on Blood Glucose Level of Diabetic Rats. Pharmacogn J. 2020;12(6):1218-22. 